\title{
An Overview of Science Challenges Pertaining to our Understanding of Extreme Geomagnetically Induced Currents
}

\author{
Chigomezyo M. Ngwira and Antti A. Pulkkinen
}

\begin{abstract}
Vulnerability of man-made infrastructure to Earth-directed space weather events is a serious concern for today's technology-dependent society. Space weather-driven geomagnetically induced currents (GICs) can disrupt operation of extended electrically conducting technological systems. The threat of adverse impacts on critical technological infrastructure, like power grids, oil and gas pipelines, and communication networks, has sparked renewed interest in extreme space weather. Because extreme space weather events have low occurrence rate but potentially high impact, this presents a major challenge for our understanding of extreme GIC activity. In this chapter, we discuss some of the key science challenges pertaining to our understanding of extreme events. In addition, we present an overview of GICs including highlights of severe impacts over the last 80 years and recent U.S. Federal actions relevant to this community.
\end{abstract}

\section{Introduction}

Concern about the vulnerability of man-made technological assets to Earth-directed extreme space weather events has significantly grown in the last two decades. For example, space weather-driven geomagnetically induced currents (GICs) that can disrupt operation of assets such as, power transmission grids, oil and gas pipelines, and telecommunication cables are a serious problem for society today (e.g., Barlow, 1849; Davidson, 1940; Boteler and Jansen van Beek, 1999; Pirjola, 2000; Molinski et al., 2000; Pulkkinen et al., 2001; Eroshenko et al., 2010, and references therein).

The ultimate challenge for the scientific community is to gain a better understanding of extreme storms to ensure that we can more accurately assess and predict the occurrence and impact of extreme events. In this chapter, we present an overview of extreme GICs that highlights some of the most pressing science challenges, known severe impacts within the last 80 years, and recent U.S. Federal actions. While the topics in this chapter touch on a wide range of space weather processes, the discussions are focused primarily on GICs. For detailed insight on certain aspects of space weather phenomena, interested readers are referred to the other chapters in this book. 


\subsection{Geomagnetic Storms at Earth}

Large, violent explosions of solar plasma from the Sun's corona, well-known as CMEs (coronal mass ejections), are the major source of strong geomagnetic storms at Earth (e.g., Gopalswamy et al., 2005). CMEs contain plasma and an embedded solar magnetic field known as the interplanetary magnetic field (IMF). The most intense disturbances are produced under southward IMF conditions when IMF orientation is oppositely directed to the Earth's magnetic field. Under southward IMF conditions, a more efficient coupling pattern is established that in turn stimulates a chain of complex dynamic processes within the magnetosphere-ionosphere (M-I) system driving phenomena such as geomagnetic disturbances (GMDs), auroral displays at high-latitude locations, ionospheric irregularities, and traveling ionospheric disturbances. CME's are recognized also as the most geoeffective driver of intense GICs (see e.g., Huttunen et al., 2008; Pulkkinen et al., 2010a; Ngwira et al., 2013a).

\subsection{Basic theory of GICs}

GICs are essentially the ground manifestation of a complex space weather chain of events initiated by solar eruptions. On a fundamental level, the key aspect of the continuous solar wind and magnetosphere interaction that drives GICs is the variation in nearspace electric current systems. Intense time-varying currents cause rapid fluctuation of the geomagnetic field on the ground. The physical principle of the flow of GICs in technological systems is governed by Faraday's law of induction: a changing magnetic field induces currents in conductors. More specifically, Faraday's law

$$
\nabla \times \mathbf{E}=-\frac{\partial \mathbf{B}}{\partial t}
$$

relates the temporal variation of the geomagnetic field to the formation of the geoelectric field. The geoelectric field then drives an electric current inside the earth according to Ohm's law $\mathbf{J}=\sigma \mathbf{E}$. The induced geoelectric field observed on the surface is independent of the technological system and depends on M-I currents, which in turn are dependent on space weather conditions, and on electromagnetic induction that is determined by the Earth's geology (e.g., Pirjola, 1982).

Overall the GIC problem demands a two-step approach (Pirjola, 2000, 2002). In step one, geophysical aspects involving the estimation of the geoelectric field based on the knowledge of magnetosphere-ionosphere currents and the Earth's geological structure are considered. Step two is the engineering piece in-which the system response is modeled based on the determined geoelectric field and detailed information about the particular ground system (e.g., Lehtinen and Pirjola, 1985; Molinski et al., 2000; Pirjola, 2000).

A simple but illustrative model for calculating the geoelectric field assumes a plane wave propagating vertically downwards and that the Earth is a uniform (or a layered) halfspace with conductivity $\sigma$ (Cagniard, 1953; Pirjola, 1982). Consider a single frequency $\omega$, then the horizontal geoelectric field $E_{y}$ component can be expressed in terms of the perpendicular horizontal geomagnetic field component $B_{x}$ as:

$$
E_{y}(\omega)=-\sqrt{\frac{\omega}{\mu_{0} \sigma}} e^{\frac{i \pi}{4}} B_{x}
$$


where $\mu_{0}$ is the permeability of free space and the layer of air between the ground and the ionosphere is considered to have zero conductivity so that there is no significant attenuation of external electromagnetic fields. Equation (1) is the "basic equation of magnetotellurics" since it outlines the basis for deriving the Earth's conductivity by using geoelectric and geomagnetic field measurements recorded at the surface.

The plane wave method is a well-established and widely used method for GIC applications (see e.g., Pirjola, 2002; Viljanen et al., 2006a; Ngwira et al., 2008; Pulkkinen et al., 2015a; da Silva Barbosa et al., 2015). Figure 1 shows a comparison of the plane wave model geoelectric field and measured field. Measured geoelectric fields were recorded at Browns Ferry station under the NSF-funded EarthScope USArray MT project. The model geoelectric fields were computed from equation 2 above using recorded geomagnetic field data and a 1-D layered Earth conductivity specific to this particular region according to Fernberg (2012). Clearly, there is a good match between the modeled and measured Ey component but the Ex component amplitudes are off even though the general trends are well captured. This example highlights the need to improve our modeling abilities.

It is important to note that the plane wave approach has also been applied to cases of extreme geomagnetic storms. For instance, it has been extensively used to study extreme GIC events (Ngwira et al., 2008; Wik et al., 2009; Pulkkinen et al., 2012; Ngwira

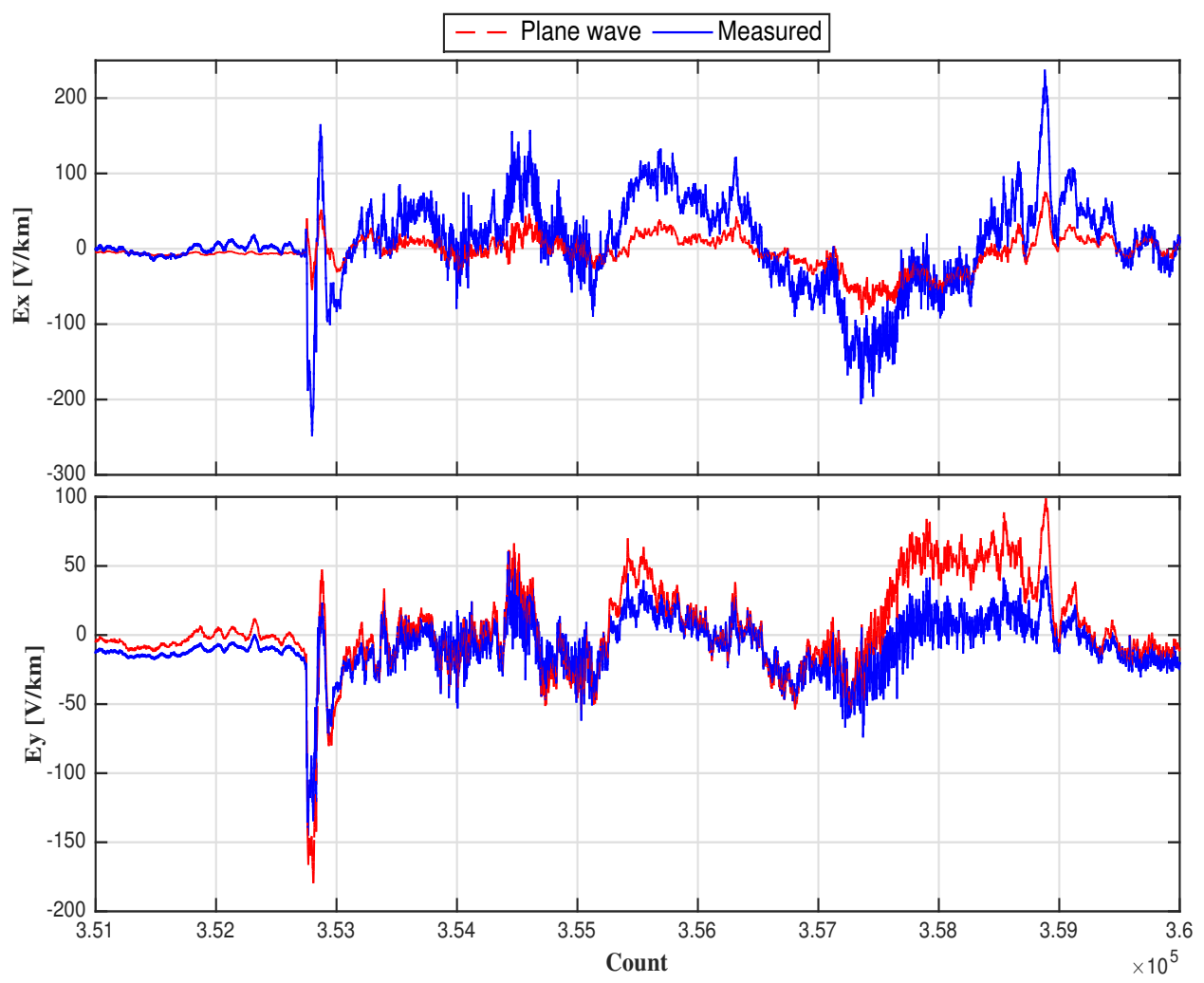

Figure 1: A comparison of modeled and measured geoelectric fields during a storm event in October 7, 2015. The measured fields were recorded at Browns Ferry USArray station. Geoelectric field measurements courtesy of Anna Kelbert, USGS. 
et al., 2013a, 2015). More recently, Ngwira et al. (2014) also employed the plane wave method to study surface geoelectric field response based on a hypothetical simulation of an extreme Carrington-type event. The modeled fields captured the global response pattern. Therefore, indications thus far suggest that the approximation can be applied also to extreme cases but further investigations are still required.

In general, information about the geoelectric field that is produced on the ground during a GMD event is obtained using the approach above. Now it is relatively straightforward to calculate the level of GICs flowing through a given node for any ground system. This purely engineering task, requiring a detailed description of the specific system, is beyond the scope of this paper. For further details regarding the execution of this process, interested readers are encouraged to consult Lehtinen and Pirjola (1985) and/or Viljanen and Pirjola (1994), and references therein.

\section{Impact on Ground Systems}

GICs have the potential to disrupt different technologies that we depend on for economic vitality and national security, including the electric power grid, oil and gas pipelines, and communications networks. This critical infrastructure makes up a diverse, complex and interdependent network of systems where a failure of one could likely impact another.

Table 1 provides a list of extreme GIC effects that have taken place over the last 80 years. The source (or reference) of this information is also included. In the rest of this section we briefly describe GIC effects on different ground systems.

\subsection{Electrical Power Systems}

It is widely acknowledged that a variety of grounded conductors can be disrupted by GICs, however, electric power systems constitute probably the most critical technological infrastructure vulnerable to these deleterious effects due to long transmission lines. For that reason electric power systems are highly singled out by many authors since electric energy cuts across many sectors of modern society and economy.

Large amplitude GICs pose a serious threat to the sustainability, reliability, and availability of electricity. The earliest publicly reported impact of GICs on power systems was recorded following the March 24, 1940 geomagnetic storm effects on North American power grids (Davidson, 1940). The primary effect of GICs is that they can push power transformers into so-called half-cycle saturation causing: (1) generation of hot-spots in the windings and/or structural components (e.g., Girgis and Ko, 1991; Lehtinen and Elovaara, 2002; Price, 2002); (2) increased reactive power consumption of the transformer (e.g., Xuzhu et al., 2001; Berge et al., 2011); and (3) injection of even and odd current harmonics into the power system (e.g., Walling and Khan, 1991; Shu et al., 1993; Bernabeu, 2014).

For the electric grid, the most serious concern is related to rarely occurring geomagnetic superstorms. Collapse of the Hydro-Quebec power network grid in Canada during the March 13, 1989 superstorm is the most serious example of the impact space weatherdriven GICs can have on power systems. The GICs produced during this superstorm caused a blackout of the entire Hydro-Quebec network on a time scale of just under two 
Table 1: Examples of extreme GIC effects on ground systems within the last 80 years.

\begin{tabular}{|c|c|}
\hline Date & Associated effects/impacts \\
\hline March 24, 1940 & $\begin{array}{l}\text { Power circuit disturbances in North America. Earliest publicly } \\
\text { reported impact on power grids. (Davidson, 1940; McNish, 1940). }\end{array}$ \\
\hline Feb. 11, 1958 & $\begin{array}{l}\text { Blown AC power supply fuses for Finnish telecommunication } \\
\text { cable system; Fire damage to telegraph equipment } \\
\text { (Nevanlinna et al., 2001; Wik et al., 2009). }\end{array}$ \\
\hline Nov. 13, 1960 & $\begin{array}{l}30 \text { Swedish high-voltage power network line breakers tripped } \\
\text { (Wik et al., 2009). }\end{array}$ \\
\hline August 4, 1972 & $\begin{array}{l}\text { Communication cable system outage in mid-western U.S. } \\
\text { (Boteler and Jansen van Beek, 1999). }\end{array}$ \\
\hline July 13-14, 1982 & $\begin{array}{l}\text { Transformers and lines tripped in the Swedish high-voltage } \\
\text { power system; Railway traffic light anomalies; Effects on } \\
\text { telecommunications (Wik et al., 2009). }\end{array}$ \\
\hline Mar. 13-14, 1989 & $\begin{array}{l}\text { Hydro-Quebec blackout; New York transformer damage; } \\
\text { Railway track anomalies } \\
\text { (Boteler, 2001a; Bolduc, 2002; Eroshenko et al., 2010). }\end{array}$ \\
\hline March 24, 1991 & $\begin{array}{l}\text { GIC }>100 \text { A measured in Finland; } 220 \mathrm{kV} \text { lines \& a } \\
\text { transformer tripped (Viljanen et al., 1999; Wik et al., 2009). }\end{array}$ \\
\hline Nov. 9, 1991 & $\begin{array}{l}220 \mathrm{kV} \text { line tripping; Large pipe-to-soil voltages in an } \\
\text { oil pipeline (Wik et al., 2009). }\end{array}$ \\
\hline April 6, 2000 & $\begin{array}{l}\text { Largest GIC on Swedish transformer; False railway track occu- } \\
\text { pations/blockages (Wik et al., 2009; Eroshenko et al., 2010). }\end{array}$ \\
\hline Nov. 6, 2001 & Railway automatic system failure (Eroshenko et al., 2010). \\
\hline Oct. $29-30,2003$ & $\begin{array}{l}\text { Malmö blackout; Excessive transformer heating; Triggered } \\
\text { emergency procedures at nuclear power plants in Canada and } \\
\text { Northeastern United States; Reported damaged to high-voltage } \\
\text { transformers in South Africa; Railway automatic system failure } \\
\text { (Pulkkinen et al. }(2005) \text {; Wik et al. }(2009) \text {; } \\
\text { Gaunt and Coetzee (2007); Eroshenko et al. (2010)). }\end{array}$ \\
\hline Nov. 20, 2003 & Railway automatic system failure (Eroshenko et al., 2010). \\
\hline Nov. 8, 2004 & $\begin{array}{l}\text { Transformer GIC exceeding } 100 \text { A measured in southern } \\
\text { Sweden ( Wik et al., 2009). }\end{array}$ \\
\hline May 14,2005 & Railway automatic system failure (Eroshenko et al., 2010). \\
\hline
\end{tabular}

minutes (Boteler, 2001a; Bolduc, 2002, and references therein). The power outage that affected millions of people for about 9-hours was the result of wide-spread transformer saturation. During the same event, a generator step-up power transformer was destroyed in New Jersey, USA.

More recently, the Halloween storm of October 2003 caused failure of a high-voltage power transmission system in Malmö, Sweden (e.g., Pulkkinen et al., 2005; Wik et al., 2009). The incident caused a power blackout that lasted for about an hour and left around 50,000 customers without electricity (Wik et al., 2009). In South Africa, at a mid-latitude location that was previously considered much less prone to GIC impacts, 
possible transformer damages were reported during the same storm of October 2003 (Gaunt and Coetzee, 2007).

The concern of any harmful impact on power grids has triggered renewed interest in extreme GICs and space weather in general (e.g., Thomson et al., 2011; Pulkkinen et al., 2012; Ngwira et al., 2013a; Marshall et al., 2012; Ngwira et al., 2014; Fiori et al., 2014; Pulkkinen et al., 2015a; Ngwira et al., 2015; Schrijver et al., 2015; Carter et al., 2016). As a result, there is growing recognition that the GIC problem is not only a high-latitude phenomenon but affects also mid- to low-latitudes (see e.g., Trivedi et al., 2007; Ngwira et al., 2008; Watari et al., 2009; Marshall et al., 2011; Torta et al., 2012; Carter et al., 2015; Adebesin et al., 2016).

In addition, the very first NASA Living With a Star (LWS) Institute Working Group that targeted the GIC problem was selected competitively as the pilot activity for the new LWS element (Pulkkinen, 2016). The new NASA LWS Institutes program element was launched in 2014. In 2015, the LWS Institute GIC Working Group held two, small working group meetings focused on well-defined problems that called for intense, direct interactions between colleagues in interdisciplinary fields. This facilitated the development of a deeper insight of the variety of processes that link solar activity to Earth's environment and the power grid. See Pulkkinen et al. (2017) for more details on the LWS Institute GIC Working Group findings, and Pulkkinen (2016) for the Special Collection of papers, a product of work by teams of researchers from more than 20 different international organizations.

\subsection{Oil and Gas Pipelines}

Oil and gas pipelines play a key role throughout the world as a mode of transporting energy commodities over long distances from their sources to the end-users or consumers. These pipelines are also affected by the GICs produced by geomagnetic disturbances whose effects are not immediate but rather may need the cumulative action of several disturbances (Boteler, 2001b; Marshall et al., 2010). Unprotected buried pipelines can be susceptible to corrosion damage (e.g., Seager, 1991; Martin, 1993; Gummow and Eng, 2002). Corrosion is an electrochemical process occurring when a current flows from the pipe into the soil (Gummow and Eng, 2002). To protect the steel pipe from corrosion, pipelines are covered by an insulating coating, in conjunction with a cathodic protection system, that keeps the pipeline at a negative voltage on the order of $1 \mathrm{~V}$ with respect to the ground. This helps to prevent telluric current (or GIC) flows from the pipeline to the soil.

Generally, there isn't much information about GIC impacts on pipelines, but one of the most extended studies of space weather effects on pipelines was conducted on the Finnish natural gas pipeline from August 1998 to May 1999 by Pulkkinen et al. (2001). The project was implemented to: (1) derive a model for computing GICs and pipe-tosoil (P/S) voltages, (2) perform measurements of GICs and P/S voltages in the pipeline, and (3) derive statistically based predictions of GIC occurrences and $\mathrm{P} / \mathrm{S}$ voltages at different locations in the pipeline network. The study concluded that the largest $\mathrm{P} / \mathrm{S}$ voltage variations occurred at the ends of pipelines, while the largest GIC flows were in the middle portions of the pipeline network. This conclusion was consistent with earlier published results by Boteler et al. (2000). 


\subsection{Other Systems}

GICs can impact also telecommunication systems (e.g., Nevanlinna et al., 2001; Karsberg et al., 1959). In fact, it is fairly well accepted that the first recorded space weather impact on human-made technology was on telegraph systems (e.g., Barlow, 1849; Prescott, 1860; Cade III, 2013). Today, optical fibre cables have a decreased probability of problems because they do not carry GIC. On the other hand, the metal wires used in conjunction with the fibre cables to provide the power needed for repeat stations might suffer from GIC-related impact.

For instance, Nevanlinna et al. (2001) report on a case of sudden interruption of two coaxial phone cable systems in the Finnish telecommunication network during the great magnetic storm of February 11, 1958. The problem was a result of blown fuses connected to the AC power feed at the repeater stations. In North America, a major geomagnetic storm on August 4, 1974 is reported to have caused an outage of a communication cable system in the mid-western U.S. (e.g., Anderson et al., 1974; Boteler and Jansen van Beek, 1999). A detailed analysis of this geomagnetic storm's response performed by Boteler and Jansen van Beek (1999) revealed that the outage was associated with a highly localized ionospheric eastward electrojet source.

On railway networks, there are very few well-documented cases concerning GIC effects (e.g., Wik et al., 2009; Eroshenko et al., 2010, and references therein). One of the earliest reports is a malfunctioning of traffic lights on Swedish railways during the great geomagnetic storm of July 1982 (see Wik et al., 2009, and references therein). A more recent event on the Russian railways was caused by an anomaly in the signal system operation across some divisions within the high-latitude regions, as documented by Eroshenko et al. (2010). The anomaly manifested as false traffic light signals about the occupation of the railways that appeared precisely during the main phases of the strongest part of the seventeen geomagnetic storms examined.

\section{U.S. Federal Actions Relating to GICs}

It can be argued that GICs are currently the greatest space weather hazard-related global concern. The concern pertains specifically to extreme storms and extreme GICs that have potential to cause significant and direct disruption of our daily lives. Also, the awareness about the threat posed by GICs has been evolving very rapidly and especially in the U.S. the elevated awareness has led to a number of policy and regulatory actions.

On the policy side, the action has been taken at the White House level in terms of development of the National Space Weather Strategy and National Space Weather Action Plan (SWAP) (National Science and Technology Council, 2015a,b). While GICs are not the only space weather hazard addressed in these policies, the phenomenon does play a central role in them. Importantly, the U.S. federal government is in the process of executing the SWAP and the initial extreme event benchmark studies that are the first step in the plan, have been completed. In the SWAP context, "extreme" is defined as a 1-in-100-year event and a theoretical maximum event characterized using key physical parameters of interest. The initial SWAP geoelectric field work related to GICs was recently reported by Love (2012). It is also worth noting that in the UK, GICs were recently introduced as a part of the space weather element in the National Risk Registry 
(Cabinet Office, 2015).

On the U.S. regulatory side, the Federal Energy Regulatory Commission (FERC) recently ordered development of GMD standards that will direct the power transmission industry response to GIC hazards (Federal Energy Regulatory Commission, 2015). In response to both industry concerns about the GIC hazard and FERC GMD order, the North American Electric Reliability Corporation (NERC) that is the key North American hub for power transmission industry's coordinated bulk system reliability actions, took the leading role in organizing industry response to the hazard. NERC work has resulted in a number of publications (e.g., North American Electric Reliability Corporation, 2012, 2013, 2016a,b) that guide industry on GIC issues. As a regulatory authority, NERC also drafts the standards in response to the FERC order. The GMD standard pertaining to hazard assessments drafted by NERC includes 1-in-100-year event benchmark that was tailored for somewhat simplified utility level usage (North American Electric Reliability Corporation, 2016a). The NERC GMD standard was approved by FERC in September 2016, which means that all U.S. utilities operating at or above $200 \mathrm{kV}$ will be addressing the hazard posed by extreme GICs.

Reflecting the actions in North America and UK, many nations around the globe have increased interest in characterizing the hazard posed by GICs. Nations such as the US, UK, Canada, Finland, Norway, Sweden, China, Japan, Brazil, Namibia, South Africa, and Australia all have launched hazards assessment campaigns to understand and mitigate the possible GIC impact on their systems. In all of these works, understanding the extremes such as 1-in-100-year events is the central theme. It is thus clear that there is a great demand for improved understanding of extreme GICs. The challenge for scientists is to characterize the spatiotemporal evolution of extreme geoelectric fields and GICs for the past, present and future (see Pulkkinen et al., 2017, for more discussion on this).

\section{$4 \quad$ Key Science Challenges}

This section elaborates on some critical science topics that continue to hinder our understanding of extreme events. Here science is perceived as the fundamental Space and Earth sciences research that enriches awareness and improved physics-based modeling of the physical processes relating to GICs. The ability to monitor, model, forecast, and understand extreme space weather events is among the most pressing scientific objectives of our highly technology-dependent society.

Over the past few decades, major advancements in understanding the processes operating within distinct regions of the near-Earth space environment and the interaction between the regions has led to a full-grown insight of the important processes driving GICs (Pulkkinen et al., 2017). However, even though they have potentially high impact, there is still limited knowledge of extreme events because they occur infrequently. As a result, there are insufficient historical recordings to adequately examine our ability to more accurately model extreme events, from which we can gain better understanding of the physical processes operating in the solar wind-magnetosphere-ionosphere coupled system.

We note that the influence of the Earth's geology on the GIC induction process is 
not addressed in the present study but a treatment of this topic is offered by Love and Bedrosian (2017) and references therein, for the benefit of interested readers.

\subsection{Extreme Drivers}

Understanding the basic principles responsible for the initiation and development of dynamic M-I currents that create intense GICs on the ground is among the most pressing science issues (e.g., Pulkkinen et al., 2017, and references therein). Two important aspects in this regard are: (1) interplanetary solar wind structures that drive extreme GICs on the ground, and (2) response of M-I processes under extreme driving.

Solar wind recordings at L1 provide key insight of external driving conditions and are fundamentally important for space weather research (Akasofu, 1981; Borovsky and Funsten, 2003; Echer et al., 2008). Solar wind changes play a central role in controlling the generation and evolution of M-I dynamics (Gonzalez, 1990; Weigel et al., 2002; Ebihara et al., 2005; Tsurutani et al., 2015). While it is generally agreed that CME-driven storms are the most geoeffective source of large GICs (e.g., Huttunen et al., 2008; Adebesin et al., 2016), it is difficult to determine when and if the response of M-I processes during "ordinary" space conditions can be applied to extreme conditions of solar wind (Nagatsuma et al., 2015).

The magnetosphere responds dramatically to major changes in the solar wind. Several studies demonstrate that the response of the M-I coupled system is more complex under extreme conditions (e.g., Chun and Russell, 1997; Ebihara et al., 2005; Ngwira et al., 2014). In an extended study of extreme geoelectric fields on the ground, a follow on study of Pulkkinen et al. (2012), Ngwira et al. (2013a) make known that rapid changes in solar wind conditions trigger strong enhancement of the equatorial electroject (EEJ) current generating intense geoelectric fields in the EEJ zone. The suggested primary mechanism for this dramatic activity is penetration of high-latitude electric fields. As well, these sudden changes in the solar wind alter the auroral electric current due to related changes in FACs generating intense GICs at high-latitudes, as recently reported by Adebesin et al. (2016). Ebihara et al. (2005) found that apart from moving to much lower latitudes than usual, FACs also developed a complex distribution structure during the superstorm on November 20, 2003. Then by simulating a Carrington-type event using the University of Michigan physics-based Space Weather Modeling Framework (SWMF) and extreme solar wind driving conditions, Ngwira et al. (2014) got similar results of complex FACs in supports of earlier findings.

Magnetospheric substorms have long been identified as one of the leading causes of intense high-latitude GICs (e.g., Pulkkinen et al., 2005; Viljanen et al., 2006b; Ngwira et al., 2014, and references therein). Substorms are elemental physical processes of solar wind energy storage and explosive release in Earth's magnetotail region, which encompass basic plasma physics. Closely related to the substorm expansion phase is the enhancement of the westward current across the bulge of expanding aurora that is fed by FACs (McPherron and Chu, 2016). Enhancement of auroral electrojet currents is a direct manifestation of the substorm current wedge (SCW) (e.g., Murphy et al., 2013; McPherron and Chu, 2016, and references therein), which is a central element of the expansion phase created by magnetic field dipolarization in the magnetotail and intensification of the westward electrojet after auroral substorm onset. 
Exactly what is driving the development of complex M-I processes and their connection to the development of extreme GICs is still open to debate and calls for further consideration. Thus, besides substorms, other major GIC drivers are also worth considering, including, geomagnetic pulsations (Pulkkinen et al., 2005; Viljanen et al., 1999; Pulkkinen and Kataoka, 2006) and sudden storm commencements (Kappenman, 2003; Pulkkinen et al., 2005; Fiori et al., 2014; Carter et al., 2015).

Now, one of the major characteristics common to most, if not all, extreme events is that peak GIC activity tends to occur in relatively isolated spots/locations (Boteler and Jansen van Beek, 1999; Pulkkinen et al., 2015a; Ngwira et al., 2015, and references therein). It is important that we grasp those fundamental processes that give rise to local, regional and global-scale structure and dynamics in the near-Earth space environment. This is one of the top priorities for space weather research today. Since the solar windmagnetosphere-ionosphere is a coupled systems, one of the issues that makes it difficult to explicate the causes is that several different mechanisms can be contributing at the same time, as Onsager et al. (2004) point out. The challenge for us is to find creative ways (or tools) to separate the different contributions with great accuracy.

The induced geoelectric field is responsible for currents that flow on ground-based systems, thus it is the primary quantity that dictates the magnitude of GICs. Figure 2

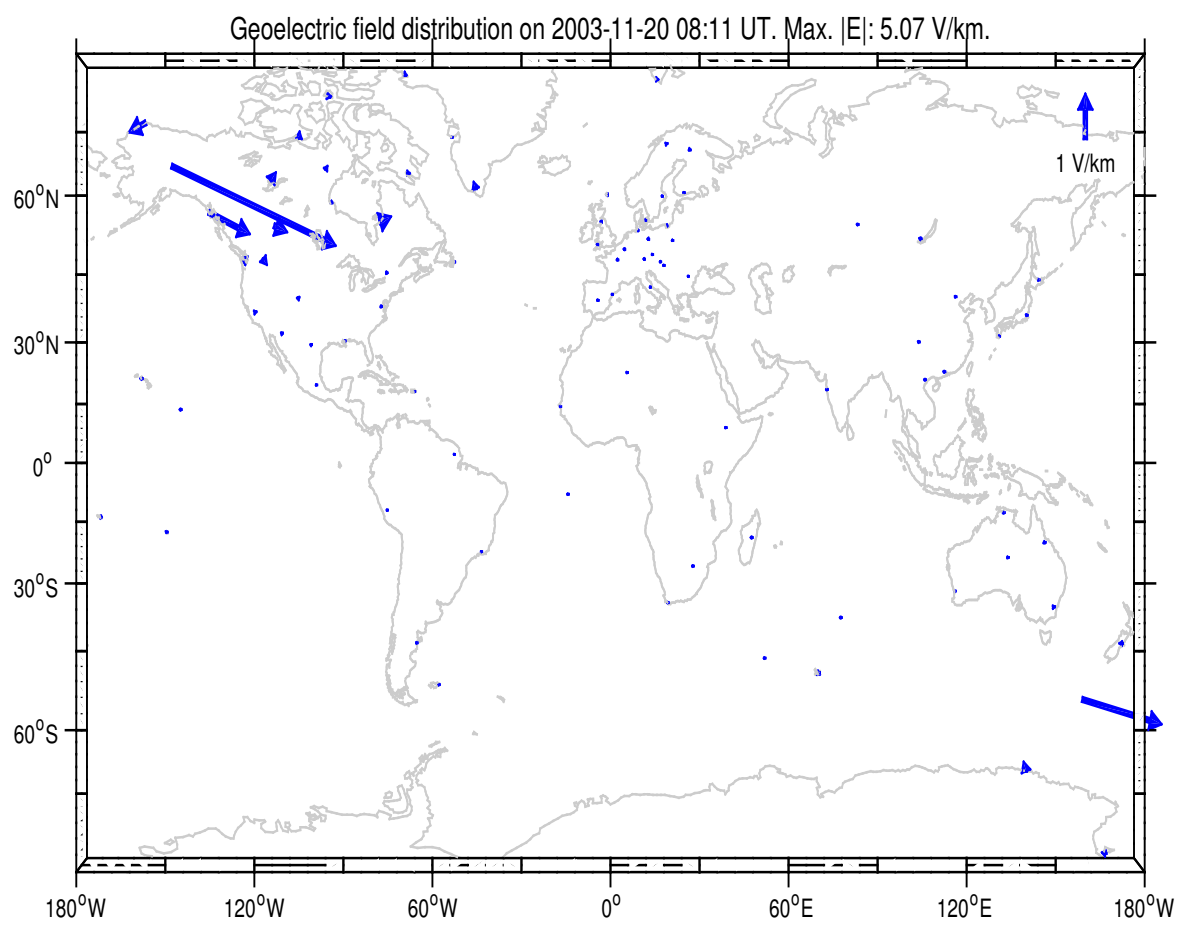

Figure 2: Calculated global geoelectric fields for 20 November 2003 showing a localized extreme high-latitude peak geoelectric field at the College magnetometer station in Alaska. Note that the peak geoelectric field amplitude indicated on the top of the figure refers to a single station maximum. 
contains an illustration of a highly localized extreme geoelectric field (or GIC event) on November 20, 2003. Ngwira et al. (2015) provide a summary of twelve localized extremes that occurred between the years 1982-2005. In the figure, a very intense geoelectric field $(>1 \mathrm{~V} / \mathrm{km})$ appears at a single site in the Alaskan region. These intense geoelectric fields are seen only at three time instants (08:10, 08:11 and 08: 12 UT). Ngwira et al. (2015) further reveal that these localized extreme fields at single sites can be associated with structures that differed greatly from global and regional average fields. However, the physical processes that control the evolution of the localized extremes have not been sufficiently explored.

Obviously, storm-time variability of the geoelectric field is a direct reflection of dynamic processes in the M-I coupled system. Consequently for GIC applications, it is critical that we understand the processes that produce complex current structures in the solar wind, magnetosphere and ionosphere. The task at hand is to establish: (1) What is the role of external extreme drivers that regulate the state of the whole system? (2) How does the M-I system respond to extreme driving? The ultimate goal is to build a better understanding of the spatiotemporal characteristics of M-I currents under extreme driving. Like most of the major scientific challenges in the geosciences, there is growing recognition that an integrated approach that consolidates multiple disciplines and multiple sets of space-based and ground-based measurements is needed to enrich our knowledge on CME's and M-I processes that amplify geomagnetic hazards.

\subsection{Modeling Extremes}

A number of GIC system flow analysis techniques exist today (Lehtinen and Pirjola, 1985; Boteler et al., 2000; Pulkkinen et al., 2001; Zhang et al., 2012; Bernabeu, 2013; Overbye et al., 2013; Boteler, 2014; Boteler and Pirjola, 2014, and references therein). A description of the geoelectric field in the near vicinity of the ground system and information about the particular network system parameters must be furnished. For this community, the geoelectric field is the foremost quantity of interest since it is the main interface between the geophysical processes and the engineering application of GIC.

Assessing the geomagnetic hazard to ground systems is often dependent on our ability to provide information to end-users about the expected extremes. Thus, modeling space weather events with sufficient lead-time and accuracy is crucial for adopting appropriate operational strategies. Achieving a more reliable forecast framework pertaining to GICs depends on our ability to model ground magnetic field perturbations with high accuracy. Significant progress has been made in the overall modeling framework both from first principles physics-based approaches and from empirical techniques (e.g., Raeder et al., 1996; Weigel et al., 2003; Pulkkinen et al., 2010b, 2013; Tóth et al., 2014; Wiltberger et al., 2015; Wintoft et al., 2015). There has been a growing number of studies that focus on modeling extreme geomagnetic events in general (e.g. Manchester IV et al., 2006; Li et al., 2005; Baker et al., 2013; Ngwira et al., 2014; Liou et al., 2014; Shen et al., 2014; Cid et al., 2014). In addition, other studies specifically focus on GICs (e.g. Ngwira et al., 2013b, 2014; Kelly et al., 2017). As pointed out in section 4.1., unlocking the mysteries of the M-I system processes under extreme driving conditions is critical for our modeling.

Extreme events in particular push the boundaries of our understanding of the physics of space weather and our ability to model extremes. Interestingly, Ngwira et al. (2014) 
$09 / 02 / 2003 \quad$ Time $=01: 20: 00$

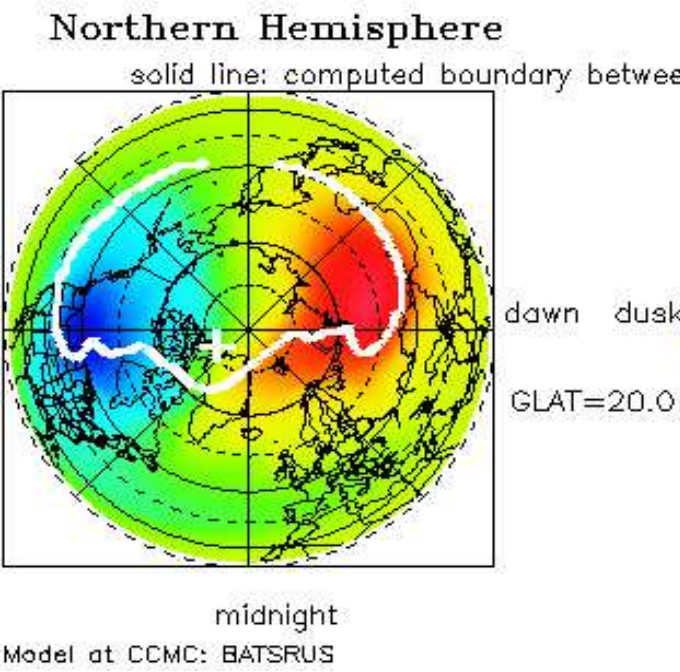

Southern Hemisphere

open and closed fieldlines

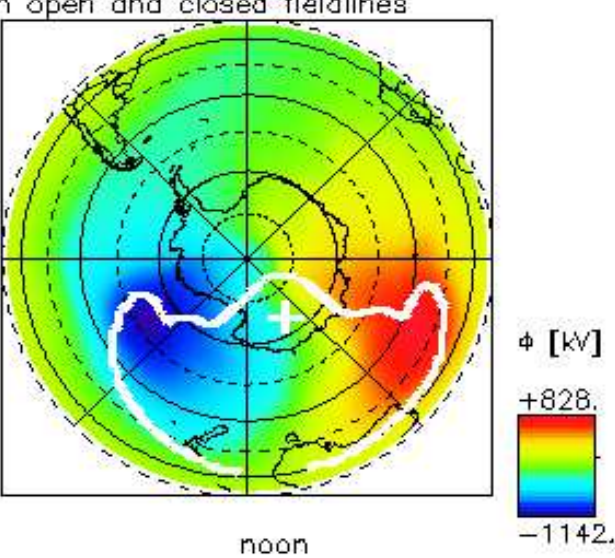

Figure 3: Ionospheric electrical potential output from MHD simulation of an extreme Carrington-type event by Ngwira et al. (2014). Geomagnetic pole is at the center of each segment and the outer circle depicts $20^{\circ}$ geomagnetic latitude. The solid white trace shows the polar cap boundary location.

found that the ionospheric cross polar cap potential (CPCP) values were much higher than normally observed but the transpolar potential relationship between the CPCP and the IMF was fulfilled with saturation occurring at substantially elevated levels. In addition, they also concluded that even under extreme driving, the MHD model was able to reproduce known ground geoelectric field global characteristic distribution (see for instance Figure 4 in Pulkkinen et al., 2012). Furthermore, Figure 3 depicts the ionospheric electric potentials in the Northern and Southern hemisphere based on simulation results by Ngwira et al. (2014). The solid white trace shows the polar cap boundary location. This figure shows that the polar cap was significantly shifted towards the dayside magnetosphere. The unusual shift of the polar boundaries could expose southern locations to high latitude ionospheric phenomena and thus also expose southern locations to elevated GIC levels.

However, many challenges remain concerning the capabilities of current models, as Welling et al. (2017) have shown. Having reanalyzed results from Pulkkinen et al. (2013) with a goal of better understanding the performance of different models, Welling et al. (2017) found that all models evaluated had a bias toward under-prediction, especially during active times. As a result, it is important to keep in mind that current models are still fairly immature and we don't know exactly how valid the results are under extreme driving conditions. Cid et al. (2014) offers an analysis and discussion of some of the key issues related to extreme storms. This has serious implications for future research targeting to improve operational forecast models.

Also, modeling short-term variability and small-scale storm-time features, which are important for GICs, is still a major challenge. Take for example results in Figure 4 which display geomagnetic field perturbations from observations (red) and model (blue) for the Bx (top) and By (middle) components. Bottom panel contains the rate of change of 


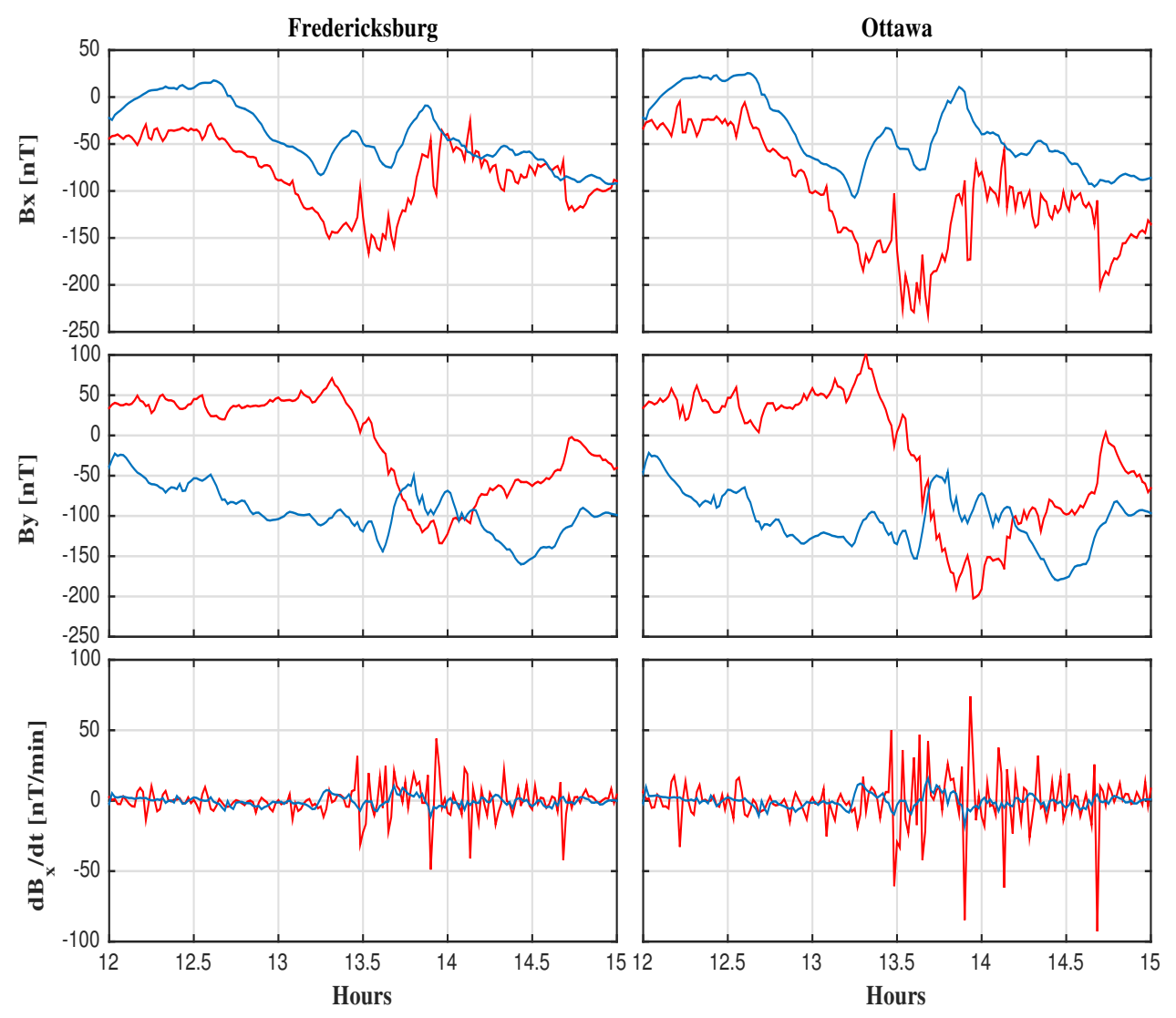

Figure 4: Example of comparison between observations (red) and SWMF model (blue) magnetic field perturbations at Fredericksburg and Ottawa for the event on March 17, 2015. Top to bottom are: magnetic field $\mathrm{Bx}, \mathrm{By}$, and $\mathrm{dBx} / \mathrm{dt}$, respectively. All the data were sampled at 1-minute resolution.

Bx component for the event on March 17, 2015. All data sets were sample at 1-minute resolution. The two stations used in the illustration are Fredericksburg, USA (left) and Ottawa, Canada (right). The model magnetic field perturbations were obtained from SWMF simulations (Tóth et al., 2012, and reference within) performed at the Community Coordinated Modeling Center (CCMC). The global magnetosphere was represented by BATSRUS (block-adaptive tree solar wind Roe-type upwind scheme: Powell et al., 1999) coupled to RCM (Rice Convection Model: Toffoletto et al., 2003) using an inner magnetosphere grid resolution of $1 / 8 \mathrm{R}_{e}$ with 2 million cells. Evidently, while the model is able to capture the envelope of the variations, the fast changes are missed. It is key to point out that similar results have been noted for other models but only SWMF outputs are shown here for illustration purposes. Nevertheless, this is a serious challenge needing further attention to improve current techniques in order to deliver highly actionable information. However, there are a number of on-going efforts to further improve these techniques (e.g., Owens et al., 2014; Devos et al., 2014; Pulkkinen et al., 2015b). 


\subsection{Defining Extremes}

Generally, there is a wide range of parameters used to define storm-time intensity, but from a GIC standpoint, it is the geoelectric field extreme that must be defined. This is because the geoelectric field intensity is closely connected to $\mathrm{dB} / \mathrm{dt}$ and not the amplitude of the storm as defined by Dst or Kp index. The Dst or disturbance storm time index is a measure of geomagnetic activity used to classify the intensity of geomagnetic storms, while $\mathrm{Kp}$ is a planetary 3-hour range index for quantifying disturbances in the horizontal geomagnetic field component.

The afforementioned point is clearly emphasized in Figure 5, which shows from top to bottom: the SYM-H index (high resolution Dst), AE index, horizontal geomagnetic field at Fort Churchill, dB/dt, and calculated geoelectric fields. At points $\mathrm{A}$ and B, strongly enhanced geoelectric fields are produced when the SYM-H levels are close to typical quiet-time or prestorm-time values but the $\mathrm{dB} / \mathrm{dt}$ is high. However, at point $\mathrm{C}$ when the SYM-H is at minimum, corresponding to peak of main phase, the geoelectric field is much lower than for case $\mathrm{A}$ and $\mathrm{B}$ with corresponding lower $\mathrm{dB} / \mathrm{dt}$. Therefore, it is critical that we develop GIC specific quantities that better define the extremes.

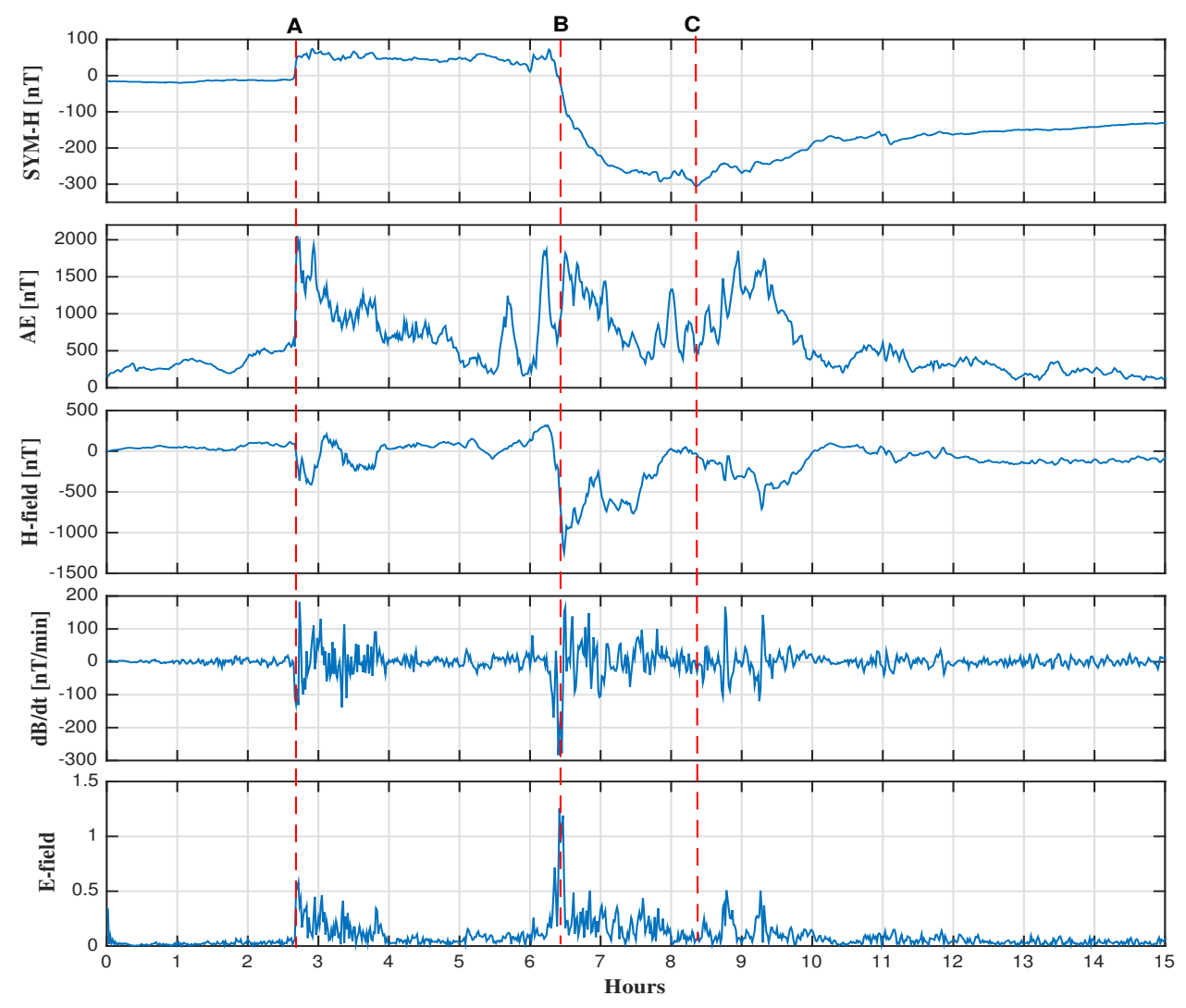

Figure 5: Plot showing the SYM-H (top) and AE (second) indices for the geomagnetic storm on May 15, 2005. The horizontal $(\mathrm{H})$ geomagnetic field, $\mathrm{dH} / \mathrm{dt}$, and the computed induced geoelectric field at Fort Churchill, Canada are shown in panels three, four and five, respectively. The letters A, B, and C mark points of interest discussed in this paper. 
However, one of the major obstacles to developing a geoelectric field-based index for predicting intensity of space weather events is that the geoelectric field is rarely measured. There are only a few places on the globe that have continuous geoelectric field recording facilities. Without these measurements, studying the spatiotemporal characteristics or later on developing regional or global geoelectric field indices is hindered. While data from MT campaigns such as EarthScope USArray MT project (http://ds.iris.edu/spud/emtf) help to alleviate some of our data challenges, long data sets that capture many storms are preferable.

\section{Concluding Remarks}

The GIC signal consists of information about the entire space weather chain since GICs are the ground manifestation of the coupled solar wind-magnetosphere-ionosphere dynamic system. The study of GIC events is therefore key also for advancing awareness of the behavior of the whole complex system.

Enriching our knowledge of the solar wind-magnetosphere-ionosphere interaction is one of the top priorities in space weather. Extreme events in particular continue to challenge our understanding of the physics of space weather. Because extreme events occur infrequently but have potentially high impact, this is a major barrier to our understanding of complex processes that produce extreme GICs. There are several on-going efforts around the world to resolve outstanding challenges we face today. However, there is still a lot more to accomplish as a community in terms of achieving understanding and later on defining extreme GICs in the context of expected impact.

To improve current understanding and modeling abilities, it is very important that we have a variety of space-based and ground-based instruments monitoring conditions from Sun to Earth and a storms progression from activity on the solar surface to its impact at Earth. Availability of quality geospace measurements of extreme events is critical for testing and interpreting space weather observations. Our limited knowledge about the temporal and spatial complexity of magnetosphere-ionosphere currents is partly because of the difficulty of making simultaneous measurements everywhere. Ideally, all electrodynamic parameters required for modeling would be recorded routinely at high resolution across the globe, but in reality, what is prevailing is a sparse collection of singlepoint measurements irregularly distributed in time and space. Therefore, acquiring more geospace observations will also help to improve the accuracy of our modeling capabilities.

\section{Acknowledgements}

Results presented in this study rely on ground-based magnetometer data obtained from INTERMAGNET. We thank the national institutes that support magnetic observatories and INTERMAGNET for promoting high standards of magnetic observatory practice. The SYM-H and AE index data are freely available from CDAWeb database hosted by the NASA-GSFC Space Physics Data Facility. The first authors is supported by NASA Grant NNG11PL10A 670.135 and NNG11PL10A 670.157 to CUA/IACS. 


\section{References}

Adebesin, B. O., A. Pulkkinen, and C. M. Ngwira (2016), The interplanetary and magnetospheric causes of extreme db/dt at equatorial locations, Geophysical Research Letters, 43, 11,501-11,509, doi:10.1002/2016GL071526.

Akasofu, S.-I. (1981), Energy coupling between the solar wind and magnetosphere, Space Science Reviews, 28.

Anderson, C. W., L. J. Lanzerotti, and C. G. Maclenna (1974), Outage of the L-4 system and the geomagnetic disturbances of August 4, 1972, The Bell System Technical Journal, 53, No. 9, 1817-1837.

Baker, D. N., X. Li, A. Pulkkinen, C. M. Ngwira, M. L. Mays, A. B. Galvin, and K. D. C. Simunac (2013), A Major Solar Eruptive Event in July 2012: Defining Extreme Space Weather Scenarios, Space Weather, 11, 1-7, doi:10.1002/swe.20097.

Barlow, W. H. (1849), On the Spontaneous Electrical Currents Observed in the Wires of the Electric Telegraph, Philosophical Transactions of the Royal Society of London, 139, 61-72.

Berge, J., R. K. Varma, and L. Marti (2011), Laboratory validation of the relationship between Geomagnetically Induced Current (GIC) and transformer absorbed reactive power, Electrical Power and Energy Conference (EPEC), 2011 IEEE, pp. 491-495.

Bernabeu, E. E. (2013), Modeling geomagnetically induced currents in the Dominion Virginia Power using extreme 100-Year geoelectric field scenarios - Part 1, IEEE Transactions on Power Delivery, 28, 1, 516-523.

Bernabeu, E. E. (2014), Single-Phase Transformer Harmonics Produced During Geomagnetic Disturbances: Theory, Modeling, and Monitoring, IEEE Transactions on Power Delivery, under review.

Bolduc, L. (2002), GIC observations and studies in the Hydro-Québec power system, Journal of Atmospheric and Solar Terrestrial Physics, 64(16), 1793-1802.

Borovsky, J. E., and H. O. Funsten (2003), Role of solar wind turbulence in the coupling of the solar wind to the Earth's magnetosphere, Journal of Geophysical Research, 108, A6, 1246, doi:10.1029/2002JA009601.

Boteler, D. H. (2001a), Space weather effects on power systems, In Song D., Singer H.J and Siscoe G.L. Space Weather. AGU Geophysical Monograph 125, pp. 347-352.

Boteler, D. H. (2001b), Assessment of Geomagnetic Hazard to Power Systems in Canada, Natural Hazards, 23, 101-120.

Boteler, D. H. (2014), Methodology for simulation of geomagnetically induced currents in power systems, Space Weather and Space Climate, 4, A21, doi:10.1051/swsc/2014018. 
Boteler, D. H., and G. Jansen van Beek (1999), August 4, 1972 revisited: A new look at the geomagnetic disturbance that caused the L4 cable system outage, Geophysical Research Letters, 26, NO. 5, 577-580.

Boteler, D. H., and R. J. Pirjola (2014), Comparison of methods for modelling geomagnetically induced currents, Annales Geophysicae, 32, 1177-1187, doi:10.5194/angeo-321177-2014.

Boteler, D. H., R. Pirjola, and L. Trichtchenko (2000), On calculating the electric and magnetic fields produced in technological systems at the Earth's surface by a "wide" electrojet, Journal of Atmospheric and Solar-Terrestrial Physics, 62, 1311-1315.

Cabinet Office (2015), National Risk Register of Civil Emergencies. Available at https://www.gov.uk/government/uploads/system/uploads/attachment_data/file/ 419549/20150331_2015-NRR-WA_Final.pdf.

Cade III, W. B. (2013), The First Recorded Space Weather Impact, Space Weather, 11, 489, doi:10.1002/swe.20091.

Cagniard, L. (1953), Basic theory of the magneto-telluric methods of geophysical prospecting, Geophysics, $18(3), 605$.

Carter, B. A., E. Yizengaw, R. Pradipta, A. J. Halford, and K. Zhang (2015), Interplanetary shocks and the resulting geomagnetically induced currents at the equator, Geophysical Research Letters, 42, doi:10.1002/2015GL065060.

Carter, B. A., E. Yizengaw, R. Pradipta, J. M. Weygand, M. Piersanti, A. Pulkkinen, M. B. Moldwin, R. Norman, and K. Zhang (2016), Geomagnetically induced currents around the world during the 17 March 2015 storm, Journal of Geophysical Research, 121, 10,496-10,507, doi:10.1002/2016JA023344.

Chun, F. K., and C. T. Russell (1997), Field-aligned currents in the inner magnetosphere: Control by geomagnetic activity, Journal of Geophysical Research, 102, A2, 226-2270.

Cid, C., J. Palacios, E. Saiz, A. Guerrero, and Y. Cerrato (2014), On extreme geomagnetic storms, Journal of Space Weather and Space Climate, 4, A28, doi: $10.1051 /$ swsc/2014026.

da Silva Barbosa, C., G. A. Hartmann, and K. J. Pinheiro (2015), Numerical modeling of geomagnetically induced currents in a brazilian transmission line, Advances in Space Research, 55, 1168-1179, doi:10.1016/j.asr.2014.11.008.

Davidson, W. F. (1940), The magnetic storm of March 24, 1940-Effects in the power system, Edison Electric Institute Bulletin, 8, 365-366.

Devos, A., C. Verbeeck, and E. Robbrecht (2014), Verification of space weather forecasting at the Regional Warning Center in Belgium, Space Weather and Space Climate, 4, A29, doi:10.1051/swsc/2014025. 
Ebihara, Y., M.-C. Fok, S. Sazykin, M. F. Thomsen, M. R. Hairston, D. S. Evans, F. J. Rich, , and M. Ejiri (2005), Ring current and the magnetosphere-ionosphere coupling during the superstorm of 20 November 2003, Journal of Geophysical Research, 110, A09S22, doi:10.1029/2004JA010924.

Echer, E., W. D. Gonzalez, and B. T. Tsurutani (2008), Interplanetary conditions leading to superintense geomagnetic storms (Dst $\leq-250 \mathrm{nT}$ ) during solar cycle 23, Geophysical Research Letters, 35, L06S03, doi:10.1029/2007GL031755.

Eroshenko, E. A., A. V. Belov, D. Boteler, S. P. Gaidash, S. L. Lobkov, R. Pirjola, and L. Trichtchenko (2010), Effects of strong geomagnetic storms on Northern railways in Russia, Advances in Space Research, 46, 1102-1110, doi:10.1016/j.asr.2010.05.017.

Federal Energy Regulatory Commission (2015), Reliability Standard for Transmission System Planned Performance for Geomagnetic Disturbance Events, 18 CFR Part 40, Docket No. RM15-11-000.

Fernberg, P. (2012), One-Dimensional Earth Resistivity Models for Selected Areas of Continental United States and Alaska.

Fiori, R. A. D., D. H. Boteler, and D. M. Gillies (2014), Assessment of GIC risk due to geomagnetic sudden commencements and identification of the current systems responsible, Space Weather, 12, 76-91, doi:10.1002/2013SW000967.

Gaunt, C. T., and G. Coetzee (2007), Transformer failure in regions incorrectly considered to have low GIC-risks, IEEE Power Tech., Conference Paper 445, Lausanne, July, pp. $807-812$.

Girgis, R. S., and C. D. Ko (1991), Calculation techniques and results of effects of GIC currents as applied to two large power transformers, Transmission and Distribution Conference, Proceedings of the 1991 IEEE Power Engineering Society, pp. 553-559.

Gonzalez, W. (1990), A unified view of solar wind-magnetosphere coupling functions, Planetary and Space Science, 38, 627-632.

Gopalswamy, N., S. Yashiro, G. Michalek, H. Xie, R. P. Lepping, and R. A. Howard (2005), Solar source of the largest geomagnetic storm of cycle 23, Geophysical Research Letters, 32, L12S09, doi:10.1029/2004GL021639.

Gummow, R. A., and P. Eng (2002), GIC effects on pipeline corrosion and corrosion control systems, Journal of Atmospheric and Solar-Terrestrial Physics, 64, 16, 17551764 .

Huttunen, K. E. J., S. P. Kilpua, A. Pulkkinen, A. Viljanen, and E. Tanskanen (2008), Solar wind drivers of large geomagnetically induced currents during solar cycle 23, Space Weather, 6, S10002, doi:10.1029/2007SW000374.

Kappenman, J. G. (2003), Storm sudden commencement events and the associated geomagnetically induced current risks to ground-based systems at low-latitude and midlatitude locations, Space Weather, 1, 3, 1016, doi:10.1029/2003SW000009. 
Karsberg, A., G. Swedenborg, and K. Wyke (1959), The infuences of Earth magnetic currents on telecommunication lines, Tele (English edition), Televerket (Swedish Telecom), No. 1, Stockholm, Sweden, 1-21.

Kelly, G. S., A. Viljanen, C. D. Beggan, and A. W. P. Thomson (2017), Understanding GIC in the UK and French high-voltage transmission systems during severe magnetic storms, Space Weather, 15, 99-114, doi:10.1002/2016SW001469.

Lehtinen, M., and J. Elovaara (2002), GIC occurrences and GIC test for $400 \mathrm{kV}$ system transformer, IEEE Transactions on Power Delivery, 17, 555-561.

Lehtinen, M., and R. Pirjola (1985), Currents produced in earthed conductor networks by geomagnetically-induced electric field, Annales Geophysicae, 3(4), 479-484.

Li, X., M. Temerin, B. T. Tsurusani, and S. Alex (2005), Modeling of 1-2 September 1859 super magnetic storm, Advances in Space Research, doi:10.1016/j.asr.2005.06.070.

Liou, K., C.-C. Wu, M. Dryer, S.-T. Wu, N. Rich, S. Plunkett, L. Simpson, C. D. Fry, and K. Schenk (2014), Global simulation of extremely fast coronal mass ejection on 23 July 2012, Journal of Atmospheric and Solar-Terrestrial Physics, 121, 32-41.

Love, J. J. (2012), Credible occurrence probabilities for extreme geophysical events: Earthquakes, volcanic eruptions, magnetic storms, Geophysical Research Letters, 39, L10301, doi:10.1130/G32655.1.

Love, J. J., and P. A. Bedrosian (2017), Geoelectric hazard maps, This Issue.

Manchester IV, W. B., A. J. Ridley, T. I. Gombosi, and D. L. De Zeeuw (2006), Modeling the Sun-Earth propagation of a very fast CME, Advances in Space Research, 38, 253262.

Marshall, R. A., C. L. Waters, and M. D. Sciffer (2010), Spectral analysis of pipe-to-soil potentials with variations of the Earth's magnetic field in the Australian region, Space Weather, 8, S05002.

Marshall, R. A., E. A. Smith, M. J. Francis, C. L. Waters, and M. D. Sciffer (2011), A preliminary risk assessment of the Australian region power network to space weather, Space Weather, 9, S10004.

Marshall, R. A., et al. (2012), Observations of geomagnetically induced currents in the Australian power network, Space Weather, 11, 1-11.

Martin, B. A. (1993), Telluric Effects on a Buried Pipeline, Corrosion, 49, (4), 349.

McNish, A. G. (1940), The magnetic storm of March 24, 1940, Terrestrial Magnetism and Atmospheric Electricity, 45, Issue 3.

McPherron, R. L., and X. Chu (2016), Relation of the auroral substorm to the substorm current wedge, Geosciences Letters, 3, 12. 
Molinski, T. S., W. E. Feero, and B. L. Damsky (2000), Shielding grids from solar storms, IEEE Spectrum.

Murphy, K. R., I. R. Mann, I. J. Rae, C. L. Waters, H. U. Frey, A. Kale, H. J. Singer, B. J. Anderson, and H. Korth (2013), The detailed spatial structure of field-aligned currents comprising the substorm current wedge, Journal of Geophysical Research, 118, 7714-7727, doi:10.1002/2013JA018979.

Nagatsuma, T., R. Kataoka, and M. Kunitake (2015), Estimating the solar wind conditions during an extreme geomagnetic storm: a case study of the event that occurred on March 13-14, 1989, Journal of Geophysical Research, 67:78, doi:10.1186/s40623-0150249-4.

National Science and Technology Council (2015a), National Space Weather Strategy, Executive Office of the President (EOP), USA. Available at https://www.whitehouse.gov/sites/default/files/microsites/ostp/final_nationalspaceweatherstrategy_20151028.pdf.

National Science and Technology Council (2015b), National Space Weather Action Plan, Executive Office of the President (EOP), USA. Available at https://www.whitehouse.gov/sites/default/files/microsites/ostp/final_nationalspaceweatheractionplan_20151028.pdf.

Nevanlinna, H., P. Tenhunenb, R. Pirjola, J.Annanpalo, and A. Pulkkinena (2001), Breakdown caused by a geomagnetically induced current in the Finnish telesystem in 1958, Journal of Atmospheric and Solar-Terrestrial Physics, 63, 1099-1103.

Ngwira, C. M., A. Pulkkinen, L. A. McKinnell, and P. J. Cilliers (2008), Improved modeling of geomagnetically induced currents in the South African power network, Space Weather, 6, S11004, doi:10.1029/2008SW000408.

Ngwira, C. M., A. Pulkkinen, F. D. Wilder, and G. Crowley (2013a), Extended study of extreme geoelectric field event scenarios for geomagnetically induced current applications, Space Weather, 11, 121-131, doi:10.1002/swe.20021.

Ngwira, C. M., A. Pulkkinen, M. M. Kuznetsova, and A. Glocer (2014), Modeling extreme "Carrington-type" space weather events using three-dimensional MHD code simulations, Journal of Geophysical Research, 119, 4456-4474, doi:10.1002/2013JA019661.

Ngwira, C. M., A. Pulkkinen, E. Bernabeu, J. Eichner, A. Viljanen, and G. Crowley (2015), Characteristics of extreme geoelectric fields and their possible causes: Localized peak enhancements, Geophysical Research Letters, 42, doi:10.1002/2015GL065061.

Ngwira, C. M., et al. (2013b), Simulation of the 23 July 2012 extreme space weather event: What if this extremely rare CME was Earth-directed?, Space Weather, 11, 671-679, doi:10.1002/2013SW000990.

North American Electric Reliability Corporation (2012), 2012 Special Reliability assessment Interim Report: Effects of Geomagnetic Disturbances on Bulk Power Systems. 
North American Electric Reliability Corporation (2013), White Paper Supporting Network Applicability of EOP-010-1, 2013. PDF available at http://www.nerc.com/pa/Stand/Pages/Project-2013-03-Geomagnetic-DisturbanceMitigation.aspx.

North American Electric Reliability Corporation (2016a), Benchmark Geomagnetic Disturbance Event Description, Project 2013-03 GMD Mitigation Standards Drafting Team, May 2016. PDF available at http://www.nerc.com/pa/Stand/Pages/Project2013-03-Geomagnetic-Disturbance-Mitigation.aspx.

North American Electric Reliability Corporation (2016b), Transformer Thermal Impact Assessment White Paper, Project 2013-03 GMD Mitigation Standards Drafting Team, May 2016. PDF available at http://www.nerc.com/pa/Stand/Pages/Project-2013-03Geomagnetic-Disturbance-Mitigation.aspx.

Onsager, T. G., A. A. Chan, Y. Fei, S. R. Elkington, J. C. Green, , and H. J. Singer (2004), The radial gradient of relativistic electrons at geosynchronous orbit, Journal of Geophysical Research, 109, A05221, doi:10.1029/2003JA010368.

Overbye, T. J., K. S. Shetye, T. R. Hutchins, Q. Qiu, and J. D. Weber (2013), Power Grid Sensitivity Analysis of Geomagnetically Induced Currents, IEEE Transactions on Power Systems, 28, NO. 4, doi:10.1109/TPWRS.2013.2274624.

Owens, M. J., T. S. Horbury, R. T. Wicks, S. L. McGregor, N. P. Savani, and M. Xiong (2014), Ensemble downscaling in coupled solar wind-magnetosphere modeling for space weather forecasting, Space Weather, 12, 395-405, doi:10.1002/2014SW001064.

Pirjola, R. (1982), Electromagnetic induction in the Earth by a plane wave or by fields of line currents harmonic in time and space, Geophysica, 18(1-2), 1-161.

Pirjola, R. (2000), Geomagnetically induced currents during magnetic storms, IEEE Trans. Plasma Sci., 28(6), 1867-1873.

Pirjola, R. (2002), Review on the calculation of the surface electric and magnetic fields and geomagnetically induced currents in ground based technological systems, Surveys in Geophysics, 23, 71-90.

Powell, K. G., P. L. Roe, T. J. Linde, T. I. Gombosi, and D. L. De Zeeuw (1999), A solution-adaptive upwind scheme for ideal magnetohydrodynamics, Journal of Computational Physics, 154(2), doi:10.1006/jcph.1999.6299.

Prescott, G. B. (1860), History, theory, and practice of electric telegraph, Boston, Ticknor and Fields.

Price, P. R. (2002), Geomagnetically induced current effects on transformers, IEEE Transactions on Power Delivery, 17, 1002-1008.

Pulkkinen, A. (2016), Introduction to NASA Living With a Star (LWS) Institute GIC Working Group Special Collection, Space Weather, Accepted for publication, doi: 10.1002/2016SW001537. 
Pulkkinen, A., and R. Kataoka (2006), S-transform view of geomagnetically induced currents during geomagnetic superstorms, Geophysical Research Letters, 33, L12108, doi:10.1029/2006GL025822.

Pulkkinen, A., A. Viljanen, K. Pajunpää, and R. Pirjola (2001), Recordings and occurrence of geomagnetically induced currents in the Finnish natural gas pipeline network, Journal of Applied Geophysics, 48, 219-231.

Pulkkinen, A., S. Lindahl, A. Viljanen, and R. Pirjola (2005), Geomagnetic storm of 29-31 October: Geomagnetically induced currents and their relation to problems in the Swedish high-voltage power transmission system, Space Weather, 3, S08C03, doi: 10.1029/2004SW000123.

Pulkkinen, A., R. Kataoka, S. Watari, and M. Ichiki (2010a), Modeling geomagnetically induced currents in Hokkaido, Japan, Advances in Space Research, 46, 1087-1093, doi: 10.1016/j.asr.2010.05.024.

Pulkkinen, A., L. Rastätter, M. Kuznetsova, M. Hesse, A. Ridley, J. Raeder, H. J. Singer, and A. Chulaki (2010b), Systematic evaluation of ground and geostationary magnetic field predictions generated by global magnetohydrodynamic models, Journal of Geophysical Research, 115, A03206, doi:10.1029/2009JA014537.

Pulkkinen, A., E. Bernabeu, J. Eichner, C. Beggan, and A. W. P. Thomson (2012), Generation of 100-year geomagnetically induced current scenarios, Space Weather, 10, S04003, doi:10.1029/2011SW000750.

Pulkkinen, A., E. Bernabeu, J. Eichner, A. Viljanen, and C. M. Ngwira (2015a), Regionalscale high-latitude extreme geoelectric fields pertaining to geomagnetically induced currents, Earth, Planets and Space, 67, 93, doi:10.1186/s40623-015-0255-6.

Pulkkinen, A., S. Mahamood, C. Ngwira, C. Balch, R. Lordan, D. Fugate, W. Jacobs, and I. Honkonen (2015b), Solar Storm GIC Forecasting: Solar Shield ExtensionDevelopment of the End-User Forecasting System Requirements, Space Weather, 13, doi:10.1002/2015SW001283.

Pulkkinen, A., et al. (2013), Community-wide validation of geospace model ground magnetic field perturbation predictions to support model transition to operations, Space Weather, 11, Issue 6, 369-385, doi:10.1002/swe.20056.

Pulkkinen, A., et al. (2017), Geomagnetically induced currents: science, engineering and applications readiness, Space Weather, Accepted for publication, doi: 10.1002/2016SW001501.

Raeder, J., J. Berchem, and M. Ashour-Abdalla (1996), The importance of small scale processes in global MHD simulations: Some numerical experiments, In The Physics of Space Plasmas, Edited by T. Chang and J. R. Jasperse, volume 14, page 403, Cambridge, Mass., 1996. MIT Cent. for Theoret. Geo/Cosmo Plasma Phys. 
Schrijver, C. J., et al. (2015), Understanding space weather to shield society: A global road map for 2015-2025 commissioned by COSPAR and ILWS, Advances in Space Research, 55, 2745-2807.

Seager, W. H. (1991), Adverse telluric effects on the northern pipelines, society of petroleum engineers. International Arctic Technology Conference, Anchorage, Alaska, SPE22178, May, p. 7.

Shen, F., C. Shen, J. Zhang, P. Hess, Y. Wang, X. Feng, H. Cheng, and Y. Yang (2014), Evolution of the 12 July 2012 CME from the Sun to the Earth: Data-constrained three-dimensional MHD simulations, Journal of Geophysical Research, 119, 7128-7141, doi:10.1002/2014JA020365.

Shu, L., L. Yilu, and J. De La Ree (1993), Harmonics generated from a DC biased transformer, IEEE Transactions on Power Delivery, 8, 725-731.

Thomson, A. W. P., E. B. Dawson, and S. J. Reay (2011), Quantifying extreme behavior in geomagnetic activity, Space Weather, 9, S10001, doi:10.1029/2011SW000696.

Toffoletto, F., S. Sazykin, R. Spiro, and R. Wolf (2003), Inner magnetospheric modeling with the Rice Convection Model, Space Science Reviews, 10\%, 175-196.

Torta, J. M., L. Serrano, J. R. Regué, A. M. Sánchez, and E. Roldán (2012), Geomagnetically induced currents in a power grid of northeastern Spain, Space Weather, 10, S06002, doi:10.1029/2012SW000793.

Tóth, G., X. Meng, T. I. Gombosi, and L. Rastätter (2014), Predicting the time derivative of local magnetic perturbations, Journal of Geophysical Research, 119, 310-321, doi: 10.1002/2013JA019456.

Tóth, G., et al. (2012), Adaptive numerical algorithms in space weather modeling, Journal of Atmospheric and Solar Terrestrial Physics, 231, 870-903.

Trivedi, N. B., et al. (2007), Geomagnetic conjugate observations of large-scale traveling ionospheric disturbances using GPS networks in Japan and Australia, Space Weather, 5, S04004, doi:10.1029/2006SW000282.

Tsurutani, B. T., R. Hajra, E. Echer, and J. W. Gjerloev (2015), Extremely intense $(\mathrm{SML} \leq-2500 \mathrm{nT})$ substorms: isolated events that are externally triggered?, Annales Geophysicae, 33, 519-524, doi:10.5194/angeocom-33-519-2015.

Viljanen, A., and R. Pirjola (1994), Geomagnetically induced currents in the Finnish high-voltage power system, Surveys in Geophysics, 15, 383-408.

Viljanen, A., O. Amm, and R. Pirjola (1999), Modeling geomagnetically induced currents during different ionospheric situations, Journal of Geophysical Research, 104, A12, 28059-28071.

Viljanen, A., A. Pulkkinen, R. Pirjola, K. Pajunpää, P. Posio, and A. Koistinen (2006a), Recordings of geomagnetically induced currents and a nowcasting service of the Finnish natural gas pipeline, Space Weather, 4, S10004, doi:10.1029/2006SW000234. 
Viljanen, A., E. I. Tanskanen, and A. Pulkkinen (2006b), Relation between substorm characteristics and rapid temporal variations of the ground magnetic field, Annales Geophysicae, 24, 725-733.

Walling, R. A., and A. N. Khan (1991), Characteristics of transformer exciting-current during geomagnetic disturbances, IEEE Transactions on Power Delivery, 6, 1707-1714.

Watari, S., et al. (2009), Measurements of geomagnetically induced current (GIC) in a power grid in Hokkaido, Japan, Space Weather, 7, S03002, S03002, doi: 10.1029/2008SW000417.

Weigel, R. S., D. Vassiliadis, and A. J. Klimas (2002), Coupling of the solar wind to the temporal fluctuations in the ground magnetic fields, Geophysical Research Letters, 29(19), 1915, doi:10.1029/2002GL014740.

Weigel, R. S., A. J. Klimas, and D. Vassiliadis (2003), Solar wind coupling to and predictability of the ground magnetic fields and their derivatives, Journal of Geophysical Research, 108(A7), 1298, doi:10.1029/2002JA009627.

Welling, D. T., B. J. Anderson, G. Crowley, A. A. pulkkinen, and L. Rastätter (2017), Exploring predictive performance: A reanalysis of the geospace model transition challenge, Space Weather, 15, 192-203, doi:10.1002/2016SW001505.

Wik, M., R. Pirjola, H. Lundstedt, A. Viljanen, P. Wintoft, and A. Pulkkinen (2009), Space Weather events in July 1982 and October 2003 and the effects of geomagnetically induced currents on Swedish technical systems, Annales Geophysicae, 27, 1775-1787.

Wiltberger, M., V. Merkin, J. G. Lyon, and S. Ohtani (2015), High-resolution global magnetohydrodynamic simulation of bursty bulk flows, Journal of Geophysical Research, 120, 4555-4566, doi:10.1002/2015JA021080.

Wintoft, P., M. Wik, and A. Viljanen (2015), Solar wind driven empirical forecast models of the time derivative of the ground magnetic field, Journal of Space Weather and Space Climate, 5, A7, doi:10.1051/swsc/2015008.

Xuzhu, D., L. Yilu, and J. G. Kappenman (2001), Comparative analysis of exciting current harmonics and reactive power consumption from GIC saturated transformers, Power Engineering Society Winter Meeting, 2001 IEEE, vol. 1, pp. 318-322.

Zhang, J. J., C. Wang, and B. B. Tang (2012), Modeling geomagnetically induced electric field and currents by combining a global MHD model with a local one-dimensional method, Space Weather, 10, S05005, doi:10.1029/2012SW000772. 